\title{
Un aperçu des récentes données probantes sur les obstacles et les facteurs favorables au dépistage du virus de l'immunodéficience humaine
}

\author{
Traversy $\mathrm{GP}^{1}$, Austin $\mathrm{T}^{1}, \mathrm{Ha} \mathrm{S}^{1}$, Timmerman $\mathrm{K}^{1 *}$, Gale-Rowe $\mathbf{M}^{1}$ \\ ${ }^{1}$ Centre de la lutte contre les maladies transmissibles et les infections, Agence de la santé publique du Canada, Ottawa \\ (Ontario)
}

${ }^{*}$ Correspondance : karen.timmerman@phac-aspc.gc.ca

\section{Résumé}

Contexte : Pour aborder la question des infections par le virus de l'immunodéficience humaine (VIH) non diagnostiquées, l'Agence de la santé publique du Canada a publié le Guide pour le dépistage et le diagnostic de l'infection par le virus de l'immunodéficience humaine en 2012, qui indiquait plusieurs obstacles et facteurs favorables au dépistage du VIH.

Objectif : Cet aperçu a pour objet de résumer les dernières données probantes sur les obstacles et les facteurs favorables au dépistage du VIH afin d'élargir la portée des recherches menées dans le cadre du Guide pour le dépistage et le diagnostic de l'infection par le VIH.

Méthodologie : Un examen de la documentation publiée entre 2010 et 2014 a été mené au moyen de Scopus, de PubMed (MEDLINE) et de la bibliothèque Cochrane. On a d'ailleurs recherché de récents rapports sur les sites Web de groupes tels que les Centers for Disease Control and Prevention, le Centre européen de prévention et de contrôle des maladies, le ministère de la Santé de l'Australie et du Vieillissement et le ministère de la santé de la Nouvelle-Zélande. Les études ont été classées en fonction de l'obstacle ou du facteur favorable déterminé et les résultats ont été résumés.

Résultats : En plus des obstacles connus, à savoir le manque de risque perçu, la gêne et le manque de connaissances, les contraintes de temps des fournisseurs, la crainte d'obtenir un résultat positif et la stigmatisation et la discrimination, de nouvelles études ont établi d'autres obstacles, notamment : la crainte de divulgation ou de manque de confidentialité, le manque d'accès, le manque de rémunération pour les fournisseurs et le manque de ressources humaines pour effectuer les tests de dépistage. Dans des études récentes, le test avec option de non-participation a été reconnu comme un facteur favorable, en plus de facteurs favorables perçus tels que l'accroissement de la sensibilisation et la normalisation du dépistage et du diagnostic de l'infection par le VIH.

Conclusion : Depuis 2010, les recherches nous ont permis d'accroître nos connaissances sur les obstacles et les facteurs favorables. Elles peuvent être appliquées pour aider à réduire le nombre d'infections par le VIH non diagnostiquées.

\section{Introduction}

Désormais, l'infection par le virus de l'immunodéficience humaine $(\mathrm{VIH})$ est largement considérée comme une maladie maîtrisable grâce aux progrès thérapeutiques. Toutefois, sans intervention adaptée, le VIH peut évoluer pour devenir le syndrome de l'immunodéficience acquise (sida), qui peut entraîner la maladie et le décès. La réduction de la propagation du $\mathrm{VIH}$ au Canada exige des efforts concertés de dépistage et de diagnostic généralisés pour identifier les personnes pouvant manquer des occasions de traitement et donc transmettre le virus à d'autres personnes sans le savoir. II est important d'offrir un diagnostic précoce du VIH 
pour préserver la qualité de vie des personnes infectées. En outre, la réduction du nombre de cas d'infection par le VIH non diagnostiquée aidera à prévenir la transmission du virus (1).

Au Canada, environ 75500 personnes vivaient avec le VIH à la fin de l'année 2014 et on estimait que $21 \%$ d'entre elles ne le savaient pas (2). En complément des initiatives actuelles visant à réduire le nombre de cas d'infection par le VIH non diagnostiquée au Canada, l'Agence de la santé publique du Canada (l'Agence) a publié le Guide pour le dépistage et le diagnostic de l'infection par le virus de l'immunodéficience humaine (le Guide) en 2012 pour appuyer les fournisseurs de soins de santé dans la normalisation du dépistage du VIH (1). Dans le Guide, on a repéré plusieurs obstacles et facteurs favorables au dépistage et au diagnostic de l'infection par le $\mathrm{VIH}$, plus précisément : le manque de risque perçu d'infection par le VIH chez les patients et les fournisseurs; la gêne et le manque de connaissances à l'égard du dépistage du VIH parmi les patients et les fournisseurs; les contraintes de temps pour les fournisseurs; les procédures fastidieuses relatives au consentement; la gestion des craintes liées à la stigmatisation ou à la discrimination associées au dépistage; et les comportements à risque en général (1).

Les études consultées pour orienter le Guide ont été publiées avant 2010 (1). Puisque la mise en œuvre et la normalisation du dépistage et du diagnostic systématiques de l'infection par le VIH demeurent une question importante pour la santé publique au Canada, on a exigé un aperçu général d'études plus récentes sur les obstacles et les facteurs favorables au dépistage du VIH. Nous avons choisi de donner un aperçu de la documentation en raison du manque d'uniformité de la définition des obstacles et des facteurs favorables dans l'ensemble des études. De plus, le chevauchement entre les obstacles et les facteurs favorables limite la capacité à effectuer un examen systématique.

Cet aperçu a pour objet de résumer les dernières données probantes concernant les obstacles et les facteurs favorables au dépistage et au diagnostic de l'infection par le VIH au Canada, et dans des pays développés semblables afin d'aider à repérer les lacunes en matière de connaissances et possiblement d'orienter les révisions futures du Guide.

\section{Méthodologie}

On a procédé à un examen de la documentation au moyen de bases de données telles que Scopus, PubMed (MEDLINE) et la bibliothèque Cochrane. Parmi les termes de recherche employés, on comptait "VIH », " virus de l'immunodéficience humaine ", " dépistage ", " diagnostic ", " obstacles », " facteurs favorables » ou « facteurs de prédiction ». Parmi d'autres sources de documentation ayant fait l'objet de recherches pour des rapports pertinents, on comptait les sites Web des Centers for Disease Control and Prevention (CDC), du Centre européen de prévention et de contrôle des maladies (ECDC), du ministère australien de la Santé et du ministère de la Santé de la Nouvelle-Zélande. Des études et des rapports provenant du Canada, des États-Unis, de l'Europe, de l'Australie et de la Nouvelle-Zélande, publiés entre 2010 et 2014, faisaient partie de l'examen de la documentation. Les éditoriaux, les commentaires et les lettres au rédacteur ont été exclus. Les principaux obstacles et facteurs favorables repérés dans chacune des études ont été examinés et classés, puis des tableaux de données probantes ont été élaborés en vue de résumer et d'organiser les principales conclusions. L'organisation des résultats de l'étude dans les catégories d'obstacles et de facteurs favorables a été confirmée par deux des auteurs du présent article, soit $\mathrm{S}$. Ha et T. Austin. Les obstacles et les facteurs favorables sont décrits dans le Tableau 1. 
Tableau 1 : Description des obstacles et des facteurs favorables

\begin{tabular}{|c|c|}
\hline Obstacles & Définition \\
\hline $\begin{array}{l}\text { Manque de risque perçu } \\
\text { d'infection par le VIH }\end{array}$ & $\begin{array}{l}\text { Pour les patients : le patient ne croit pas qu'il risque de contracter le VIH ou il croit } \\
\text { que ses comportements lui permettent de prévenir les risques. } \\
\text { Pour les fournisseurs : le fournisseur ne croit pas que son patient risque de } \\
\text { contracter le VIH, ou suppose que le risque est faible, ou il peut également croire que } \\
\text { le VIH ne pose aucun problème pour sa population de patients ou la région dans } \\
\text { laquelle il exerce sa pratique. }\end{array}$ \\
\hline $\begin{array}{l}\text { Gêne de discuter du VIH } \\
\text { ou manque de } \\
\text { connaissances }\end{array}$ & $\begin{array}{l}\text { Pour les patients : le patient ne se sent pas à l'aise de discuter du VIH ou d'autres } \\
\text { questions en matière de sexualité avec le fournisseur et il peut avoir un manque de } \\
\text { connaissances générales sur le VIH ou ne pas savoir où et comment subir un test de } \\
\text { dépistage. } \\
\text { Pour les fournisseurs : le fournisseur se sent gêné ou anxieux de poser des } \\
\text { questions de nature sexuelle au patient ou de susciter la crainte chez ce dernier en ce } \\
\text { qui a trait au VIH. II peut manquer de connaissances sur les procédures de } \\
\text { consentement, la façon de gérer des résultats positifs et les procédures de } \\
\text { déclaration pour son territoire de compétence. En outre, il peut penser qu'un manque } \\
\text { de formation précise l'empêche de procéder au dépistage du VIH. }\end{array}$ \\
\hline $\begin{array}{l}\text { Contrainte de temps pour } \\
\text { les fournisseurs de soins } \\
\text { de santé }\end{array}$ & $\begin{array}{l}\text { Les fournisseurs de soins de santé n'ont pas suffisamment de temps pour le } \\
\text { dépistage du VIH et la consultation connexe. Ils ont d'ailleurs des priorités } \\
\text { concurrentes pendant les visites qui les empêchent de procéder au dépistage du VIH. }\end{array}$ \\
\hline $\begin{array}{l}\text { Peur, stigmatisation et } \\
\text { discrimination }\end{array}$ & $\begin{array}{l}\text { Le patient craint d'obtenir des résultats positifs, de subir des répercussions sociales } \\
\text { s'il demande un dépistage ou s'il est infecté (discrimination, rejet), de ne pas être } \\
\text { capable de faire face aux résultats ou bien de voir une personne qu'il connaît à la } \\
\text { clinique. }\end{array}$ \\
\hline Accès aux tests & $\begin{array}{l}\text { Une incapacité d'accéder aux tests en général (zone éloignée ou rurale, absence } \\
\text { d'assurance maladie [études menées aux États-Unis], heures d'ouverture du lieu de } \\
\text { dépistage, barrières linguistiques) ou une incapacité d'accéder à une variété de } \\
\text { services de dépistage qui sont habituellement offerts (p. ex. manque de lieux de } \\
\text { dépistage anonyme dans les zones rurales par rapport aux zones métropolitaines) } \\
\text { posent un obstacle au dépistage. }\end{array}$ \\
\hline $\begin{array}{l}\text { Contraintes en matière de } \\
\text { ressources financières et } \\
\text { humaines }\end{array}$ & $\begin{array}{l}\text { Des cas où les fournisseurs ne peuvent pas effectuer le dépistage du VIH en raison } \\
\text { d'un manque de rémunération ou ils ne sont pas capables d'exécuter des initiatives } \\
\text { de dépistage du VIH en raison d'un manque de personnel. }\end{array}$ \\
\hline Facteurs favorables & Définition \\
\hline $\begin{array}{l}\text { Normalisation du } \\
\text { dépistage du VIH }\end{array}$ & $\begin{array}{l}\text { Réduire la stigmatisation entourant le VIH en faisant du dépistage un test routinier } \\
\text { (comme pour les tests de cholestérol, par exemple). Offrir le dépistage dans le cadre } \\
\text { de soins réguliers. }\end{array}$ \\
\hline $\begin{array}{l}\text { Test avec option de } \\
\text { non-participation }\end{array}$ & $\begin{array}{l}\text { Le dépistage du VIH est offert et effectué à moins que le patient ne refuse } \\
\text { expressément de le subir. }\end{array}$ \\
\hline $\begin{array}{l}\text { Connaissances } \\
\text { approfondies et } \\
\text { sensibilisation accrue }\end{array}$ & $\begin{array}{l}\text { Le matériel didactique axé sur les patients permet d'approfondir leurs connaissances, } \\
\text { d'être plus susceptibles de voir les aspects positifs du dépistage du VIH et d'accroître } \\
\text { l'intérêt à subir un test. } \\
\text { Le matériel axé sur les fournisseurs permet d'améliorer la formation sur le dépistage } \\
\text { du VIH et la communication entre le fournisseur et le patient. }\end{array}$ \\
\hline
\end{tabular}

\section{Résultats}

En tout, on a repéré 34 études et rapports sur les obstacles et les facteurs favorables au dépistage du VIH, dont la majorité provenait des États-Unis, tandis qu'un nombre moins élevé d'études et de rapports 
provenaient de pays européens et de l'Australie. Un rapport et une étude provenaient du Canada et on n'a trouvé aucun document de la Nouvelle-Zélande.

\section{Obstacles}

\section{Manque de risque perçu d'infection par le VIH}

Un obstacle important au dépistage du VIH est le manque de risque qui perçu découle de l'incapacité d'évaluer les niveaux de risque avec exactitude pour soi-même (par les patients ou les clients) ou pour les patients (par les fournisseurs de soins de santé). Dans un examen systématique d'études européennes par Deblonde et al., la perception d'un faible risque était considérée comme étant un obstacle dans 4 (de 24) études analysées (3). Dans un sondage mené auprès de 629 Européens ayant récemment reçu un diagnostic de $\mathrm{VIH}, 73 \%$ des répondants ont indiqué qu'ils n'avaient pas précédemment subi un test de dépistage du VIH en raison de la perception d'un faible risque (4). Selon un sondage réalisé en Australie auprès de 519 hommes séronégatifs, $41,2 \%$ des répondants ont révélé qu'ils avaient évité ou reporté le dépistage parce qu'ils ne croyaient pas avoir adopté des comportements à risque (5). De même, on a examiné, dans le cadre de plusieurs études américaines fondées sur des entrevues, les obstacles au dépistage initial chez les patients souffrant du $\mathrm{VIH} /$ sida ou les facteurs qui ont contribué au diagnostic tardif de l'infection par le VIH chez les personnes ayant contracté le sida dans les 12 mois suivant le diagnostic du VIH (6-8).

La perception d'un risque faible est un thème récurrent parmi ces études (6-8). Ce facteur a été mentionné par 14 des 41 personnes interrogées dans une étude réalisée à San Francisco et par 89 des 139 personnes interrogées dans le cadre d'une autre étude menée à New York $(7,8)$. Des fournisseurs de soins de la santé de la Caroline du Nord interrogés par White et al. ont aussi indiqué que la perception d'un risque faible était un facteur dissuadant les patients de subir un test routinier (9). En outre, il a été suggéré, par suite d'entrevues avec des fournisseurs de soins primaires, des spécialistes des maladies infectieuses et des résidents de médecine interne, que la perception d'un faible risque des patients pose un défi pour le dépistage $(10,11)$. Par conséquent, les patients qui perçoivent leur risque d'infection par le VIH comme étant faible sont moins susceptibles de subir un test de dépistage du VIH.

En revanche, l'évaluation inadéquate du risque par les fournisseurs de soins de santé peut également constituer un obstacle. D'après les résultats d'entrevues et de sondages réalisés auprès de fournisseurs de soins de la santé, une perception inexacte du risque ou une perception d'un faible risque constituait un obstacle commun au dépistage du $\mathrm{VIH}$. À l'occasion d'un sondage mené auprès de 221 fournisseurs de soins de la santé à Washington, $57 \%$ ont convenu que le fait de percevoir le patient comme étant à faible risque était un obstacle au dépistage (12). On a également considéré les fausses hypothèses sur les risques des patients comme un obstacle par suite d'entrevues à questions ouvertes avec 24 fournisseurs de soins de santé au Mississippi et au Rhode Island (13). Dans le cadre d'un sondage réalisé auprès de coordonnateurs du dépistage du $\mathrm{VIH}$, de directeurs de programme, d'infirmières gestionnaires et de directeurs de laboratoire dans des hôpitaux, des organismes communautaires et des cliniques ou centres de santé à Washington, DC, et à Houston, au Texas, on a constaté qu'un obstacle fréquemment sélectionné était le fait que le VIH ne posait pas de problème pour la population de patients $(68,6 \%$ à Washington et $20,9 \%$ à Houston) (14). De même, on a étudié les raisons pour lesquelles les stagiaires étaient encouragés ou non à effectuer des tests de dépistage du $\mathrm{VIH}$ routiniers dans le cadre d'un sondage réalisé auprès de 515 éducateurs cliniques de la Society of General Internal Medicine aux États-Unis. La perception d'une faible prévalence locale constituait la raison la plus courante pour laquelle on n'encourageait pas les stagiaires à effectuer des tests routiniers (15).

\section{Gêne et manque de connaissances}

Le manque de connaissances est un obstacle important pour les patients qui a une incidence sur les autres obstacles. Au cours d'un sondage réalisé aux États-Unis auprès de 443 adultes dans neuf cliniques universitaires de médecine interne, on a constaté que d'importants indicateurs prévisionnels de cas autodéclarés de dépistage du VIH étaient les connaissances du patient à l'égard du VIH (rapport de cotes $[R C]=1,3)$ et les demandes de test de dépistage des patients $(R C=103,3)(16)$. Par conséquent, les auteurs suggèrent que « de simples incitations dans la salle d'attente (demander un test de dépistage du 
VIH) et des campagnes de sensibilisation du public peuvent constituer des interventions plus efficaces pour accroître les taux de dépistage du VIH » (16). Le manque de connaissances peut également être un facteur en ce qui a trait à l'endroit où se rendre pour un dépistage, ce qui a été décrit comme un obstacle dans l'examen systématique mené par Deblonde et al. (3). De plus, le fait que le patient refuse de subir un test ou n'est pas à l'aise d'en discuter a été cité comme un obstacle dans une étude américaine (14).

On a repéré plusieurs obstacles aux tests de dépistage du VIH routiniers relativement aux connaissances et au degré d'aise des fournisseurs de soins de santé. Dans des études menées aux États-Unis, le manque de familiarité avec la réglementation locale sur les procédures de dépistage du VIH et les désaccords avec les recommandations nationales étaient considérés comme des obstacles au dépistage du $\mathrm{VIH}(15,17,18)$. L'anxiété relativement à la proposition du dépistage du VIH dans un milieu de soins primaires était un obstacle découlant d'un examen systématique (3). De même, lors d'entrevues avec des fournisseurs de soins de santé au Mississippi, au Rhode Island et au Massachusetts, la gêne d'amorcer des conversations sur le dépistage du VIH a été désignée comme un obstacle $(13,19)$. D'autres études réalisées aux États-Unis et en Europe suggèrent que les craintes quant à la façon de composer avec des résultats positifs, de même que des sentiments de manque d'expérience ou de manque de formation relativement aux procédures et aux règlements, peuvent constituer un obstacle pour les fournisseurs de soins de santé $(11,13,17,18,20,21)$.

\section{Contrainte de temps pour les fournisseurs de soins de santé}

Les fournisseurs de soins de santé ont souvent des contraintes de temps et doivent jongler avec des priorités concurrentes pendant les visites aux patients. La longueur des procédures relative au consentement (selon la réglementation locale) ainsi que des procédures de counseling prétest et post-test peut entraîner un manque de temps $(9,12,15,17,18,20,22,24)$. Les fournisseurs de soins de santé peuvent considérer ce manque de temps comme un obstacle s'ils ne connaissent pas très bien la réglementation locale (p. ex. s'ils ne savent pas qu'un test ne requiert qu'un consentement verbal, ils peuvent avoir le sentiment que la procédure requise pour obtenir le consentement du patient est plus longue qu'elle ne l'est en réalité).

\section{Peur, stigmatisation et discrimination}

Quand les patients craignent que leurs résultats soient positifs, il se peut qu'ils soient moins enclins à demander un test de dépistage du VIH $(3,5,25)$. Par conséquent, la peur du test lui-même ou de la possibilité que le résultat soit positif peut constituer un obstacle, en plus de la peur de faire l'objet d'une discrimination ou d'être stigmatisé. Les études récentes ont montré que la peur de la discrimination ou de la stigmatisation par la collectivité a émergé comme constituant un obstacle au test de dépistage du VIH et peut dissuader un patient de faire une demande de dépistage (25-27). Cela est en particulier vrai dans les petites localités, où le patient est susceptible de rencontrer des personnes qu'il connaît au cours de la procédure (23). La peur des répercussions sociales de la positivité du test est un obstacle très communément mentionné, à la fois par les patients et par les fournisseurs de soins de santé $(4,7,9,11,22,26,28,29)$.

La peur de la divulgation des résultats et du manque de confidentialité est un autre obstacle au dépistage du VIH $(3,4,27)$. Les jeunes ont peut-être d'autant plus de raisons de s'inquiéter que certains membres du personnel ne sont pas au courant des pratiques relatives à la confidentialité du test. Dans le cadre d'une étude sur les obstacles au dépistage du VIH chez les jeunes à New York, 131 représentants de sites offrant le dépistage ont été interrogés par la méthode du client mystère. En tout, $14 \%$ ont donné de mauvais renseignements ou ne savaient pas répondre à la question quand on leur demandait si les parents pouvaient découvrir les résultats du test (30). Les craintes relatives au respect de l'anonymat sont aussi le reflet des peurs de la stigmatisation associée au test et de la possible discrimination de la part des membres de la famille ou des collectivités. Des fournisseurs de soins de santé interrogés dans le cadre d'une étude laissaient entendre que le fait d'assurer aux patients la confidentialité du test s'avérait être un élément facilitateur très important (13). II est possible que les craintes des patients liées à la stigmatisation, aux conséquences d'un résultat positif et à la confidentialité soient aussi le résultat d'un manque de connaissances (p. ex. les patients ne savent pas toujours qu'il est tout à fait possible de vivre une longue vie 
en bonne santé avec les traitements actuels du $\mathrm{VIH}$, dans le cas d'un résultat positif). On voit ainsi qu'il existe un chevauchement des obstacles.

\section{Accès aux tests}

II n'est peut-être pas aussi facile pour les gens qui vivent dans des zones rurales ou isolées d'accéder à divers tests de dépistage du VIH que pour les habitants de métropoles plus densément peuplées. Des fournisseurs de soins de santé du Mississippi suggèrent ainsi que le fait de devoir faire de nombreux kilomètres pour accéder à des services de dépistage est un obstacle pour les patients de leur territoire (11). Une autre étude américaine s'intéressant aux personnes ayant reçu un diagnostic tardif montre que les gens vivant dans une région rurale reçoivent plus souvent un diagnostic tardif que les gens en milieu urbain (31). Sur le même thème, une étude australienne a montré que la présence d'un cabinet dans une région métropolitaine est associée à plus de dépistage du VIH que la présence d'un cabinet dans une zone non métropolitaine $(\mathrm{RC}=1,4)(32)$.

Dans une étude canadienne sur les obstacles que les femmes rencontrent à l'égard du dépistage du VIH, l'auteur souligne que le dépistage anonyme n'est peut-être pas disponible partout (26). Des adolescents ayant reçu un dépistage du VIH dans un service d'urgences ont été interrogés $(n=114)$. Quatre-vingt pourcent se sont dits plus susceptibles de demander un dépistage si une version rapide du test était disponible (33). Dans une étude, Hyden et al. ont interrogé 131 représentants de sites de test de dépistage du VIH à New York. Seulement $12 \%$ des sites offraient des tests hors des heures normales de bureau, soit de $8 \mathrm{~h} 30$ à $17 \mathrm{~h}$ du lundi au vendredi (30). En outre, $23 \%$ de ces sites ne proposaient le dépistage qu'en semaine, entre $9 \mathrm{~h}$ et $15 \mathrm{~h}$. Ainsi, les heures d'ouverture des sites de dépistage pourraient représenter un obstacle significatif pour les jeunes qui sont à l'école, de même que pour les personnes qui n'ont pas la possibilité de s'absenter du travail en semaine. Dans une enquête réalisée en Australie auprès d'hommes séronégatifs, 15,2 \% des participants évoquaient la difficulté d'obtenir un rendez-vous comme une raison de reporter le dépistage (5). Les fournisseurs de soins de santé ont aussi remarqué que la langue peut être une barrière supplémentaire à l'accès au dépistage du VIH $(12,18,34)$.

\section{Contraintes en matière de ressources financières et humaines}

Les fournisseurs de soins de santé mentionnent fréquemment le manque de ressources ou de rémunération comme obstacle personnel et institutionnel. Avoir les ressources financières et physiques, ainsi qu'avoir le personnel suffisant pour soutenir des initiatives de dépistage du VIH de routine dans un hôpital ou dans une clinique communautaire s'avère être un obstacle d'après des études américaines et européennes $(3,13,14$, $18,20)$. Les fournisseurs de soins de santé ont aussi parlé du manque de rémunération pour le temps supplémentaire accordé au test de dépistage du VIH et aux procédures associées comme d'un obstacle $(9,11,22,23)$. Puisqu'il n'y a pas d'étude canadienne récente dans le domaine, il est difficile de savoir si ces questions seraient considérées comme des obstacles au Canada.

Un résumé des études récentes sur les obstacles au test de dépistage du VIH est présenté à l'Annexe 1.

\section{Facteurs favorables}

\section{Normalisation du dépistage du VIH}

L'Agence, le CDC et le ECDC recommandent la normalisation du dépistage du VIH l'intégrant aux soins courants $(1,22,35)$. Inclure le dépistage du $\mathrm{VIH}$ dans le cadre des soins courants aurait plusieurs avantages en ce sens qu'un dépistage normalisé ne réduit pas seulement la stigmatisation associée au VIH, mais rend également les gens plus réceptifs à l'idée du test de dépistage et à l'idée de se faire dépister

$(1,10,16,29,33)$. Plusieurs sources ont mis en évidence que les patients sont plus susceptibles de subir un test de dépistage si on le leur propose plutôt que s'ils doivent le demander eux-mêmes $(16,29,33)$. D'après Haines et al.,67\% des adolescents interrogés déclarent qu'ils sont plus susceptibles de subir le test de dépistage si on le leur propose plutôt que s'ils doivent le demander eux-mêmes (33).

Un lien a été fait entre la normalisation du test de dépistage du VIH et la réduction de la stigmatisation chez les patients qui le passent. Dans une enquête sur les Écossais ayant des relations sexuelles avec d'autres hommes, les hommes qui ont subi le test l'année précédente ont moins peur d'obtenir un résultat positif que 
les autres. En outre, le nombre de tests réalisés dans cette tranche était proportionnellement supérieur à celui des hommes ayant subi le test plus d'un an auparavant ou à celui des hommes ne l'ayant jamais subi (36). Selon d'autres études, le dépistage du VIH ne devrait pas être considéré différemment des tests pour déterminer le niveau de glycémie ou de cholestérol ou la tension artérielle (17).

\section{Test avec option de non-participation}

Avec l'option de non-participation, le dépistage du VIH est offert et administré à moins d'être explicitement refusé par le patient. L'option de non-participation a été identifiée comme facteur potentiel favorable au dépistage du VIH. En effet, elle supprime l'exigence relative aux procédures de consentement plutôt longues qui constitue un obstacle pour les fournisseurs de soins de santé et les patients. Cette option règle le problème du manque de temps et répond aux inquiétudes liées à la rémunération pour le temps supplémentaire passé avec le patient. Bien que l'option de non-participation puisse être efficace pour augmenter le volume du dépistage du VIH (3), il est important que les patients aient la possibilité de consentir au test et d'en comprendre les répercussions. Certaines provinces et certains territoires du Canada ont déjà adopté une stratégie de non-participation pour le dépistage prénatal du VIH (26).

\section{Connaissances approfondies et sensibilisation accrue}

II pourrait être utile d'augmenter la disponibilité du matériel d'application des connaissances pour le VIH afin d'augmenter la sensibilisation et de souligner les bénéfices du dépistage. Les patients sont plus enclins à subir le test de dépistage quand ils en connaissent les bénéfices et quand ils sont bien renseignés sur le virus (p. ex. efficacité des traitements antirétroviraux, méthodes de réduction des risques de transmission)

(34). Les travaux de Adam et al. ont permis de découvrir qu'une plus grande connaissance du virus était associée à une meilleure routine de dépistage chez les hommes ayant des relations sexuelles avec d'autres hommes (37). Des études s'intéressant aux facteurs de prédiction du dépistage du VIH laissent entendre que les gens sont plus susceptibles de demander un dépistage s'ils y voient des conséquences positives (p. ex. protection de la famille, tranquillité d'esprit) que s'ils y voient des conséquences négatives (p. ex. stigmatisation) $(29,37)$. D'après des études examinant les facteurs favorables et les facteurs associés au dépistage récent du $\mathrm{VIH}$, l'amélioration des connaissances des patients et des fournisseurs de soins de santé grâce à la documentation et à la formation sur le VIH pourrait être un facteur favorable $(13,17,23)$. Les fournisseurs de soins de santé trouvent que l'intérêt des patients et leur disposition à subir le test, ainsi que leur connaissance de la réglementation locale en matière de consentement et de counseling sont des facteurs facilitant le dépistage $(13,23)$.

Sans surprise, les fournisseurs de soins de santé perçoivent l'amélioration de leur formation sur le VIH, l'enrichissement de leur communication, l'augmentation de la disponibilité de la documentation pour euxmêmes et les patients et les initiatives pédagogiques à l'intention de ces derniers comme de possibles facteurs favorisant le dépistage $(13,17,23)$. Le Guide recommande de rationaliser l'offre de renseignements avant le test par des ressources imprimées et vidéo, ainsi que sur mobile et en ligne (1).

Un résumé des études récentes sur les facteurs favorables au test de dépistage du VIH est présenté à l'Annexe 2.

\section{Discussion}

Notre aperçu de la littérature récente confirme l'importance des obstacles relevés dans le Guide pour le dépistage et le diagnostic de l'infection par le $\mathrm{VIH}$ : risque pas bien évalué, gêne et manque de connaissances, contrainte de temps pour les fournisseurs de soins de santé, peur, stigmatisation et discrimination. La peur de la divulgation ou du manque de confidentialité, la difficulté d'accès, le manque de rémunération pour les fournisseurs et le manque de ressources humaines pour mener les initiatives de dépistage sont d'autres obstacles repérés dans cet examen.

Pour ce qui est des facteurs favorables, le Guide recommande la normalisation du dépistage et du test du $\mathrm{VIH}$ et mentionne le renforcement de la sensibilisation (p. ex. en soulignant le fait que l'infection par le VIH est un état chronique maîtrisable), mais parle peu du test avec option de non-participation comme d'un potentiel facteur favorable (1). Cet examen a établi que le test avec option de non-participation est un 
facteur favorable en ce qu'il aplanit certains obstacles importants. Bien que cette approche soit utilisée dans certaines régions au Canada dans le cadre d'un dépistage prénatal, il n'est pas certain que l'option de non-participation pour la population générale entraîne une amélioration significative de l'identification des personnes séropositives.

L'une des forces de l'aperçu actuel est qu'il fait le point sur ce que l'on a appris sur les obstacles et les facteurs favorables au dépistage et au test du VIH depuis la création du Guide en 2012. Toutefois, cet aperçu présente un inconvénient : il ne fait référence qu'à des pays à revenu élevé, ce qui peut limiter la généralisabilité mondiale des résultats. Les résultats restent pertinents pour le Canada. Par ailleurs, le risque de biais n'a pas été évalué systématiquement dans les études utilisées, mais cet aperçu vise à faire le point sur les données recueillies, non pas à évaluer la qualité de ces données.

Cette étude a repéré un certain nombre de domaines sur lesquels se pencher par la suite. Pour commencer, ces résultats pourraient servir à éclairer les prochaines parutions du Guide et pourraient servir à d'autres organismes dans l'élaboration de leur programmation. Par la suite, il est important de repérer les principaux obstacles au dépistage et de les connaître, et d'autres recherches pourraient être réalisées dans le but d'examiner et d'évaluer les interventions visant à supprimer ces obstacles ( $p$. ex. campagnes, produits d'application des connaissances, etc.). Par ailleurs, des stratégies de dépistage du VIH comme le dépistage en couple ou l'autoadministration de tests de dépistage n'ont pas été identifiées comme facteurs favorables dans le présent examen. À l'avenir, il serait intéressant d'évaluer les mérites de ces stratégies. Pour finir, il faut souligner que les études canadiennes étaient globalement peu nombreuses, c'est pourquoi il serait utile de mener une étude pour confirmer la pertinence des obstacles et des facteurs favorables dans le contexte canadien.

\section{Conclusion}

Il est essentiel de comprendre les obstacles et les facteurs favorables au dépistage du VIH pour que les gens soient plus nombreux à se faire tester. En effet, ils peuvent renforcer l'efficacité des stratégies et faire diminuer le nombre des personnes infectées ignorant leur état sérologique (21\%) (2). Des interventions ciblées pourraient être mises en place afin de réduire les obstacles au dépistage et de tirer parti des facteurs favorables.

\section{Remerciements}

Les auteurs souhaitent remercier Jun Wu et Simon Foley de l'Agence de la santé publique du Canada pour leur aide dans l'élaboration de cet article.

\section{Conflit d'intérêts}

Aucun

\section{Financement}

Les auteurs n'ont aucune source de financement extérieure à déclarer.

\section{Références}

(1) Public Health Agency of Canada (PHAC). Human Immunodeficiency Virus-HIV Screening and Testing Guide. Ottawa, ON: PHAC; 2012. (Disponible en français : http://www.catie.ca/sites/default/files/FR_Guide-pour-ledepistage-et-le-diagnostic-de-linfection-par-le-VIH-2013.pdf)

(2) Public Health Agency of Canada (PHAC). Summary: Estimates of HIV Prevalence and Incidence in Canada, 2011. Ottawa, ON: PHAC; 2012. (Disponible en français : http://www.phac-aspc.gc.ca/aidssida/publication/survreport/estimat2011-fra.php)

(3) Deblonde J, De Koker P, Hamers FF, Fontaine J, Luchters S, Temmerman M. Barriers to HIV testing in Europe: A systematic review. Eur J Pub Health. 2010;20(4):422-32.

(4) Deblonde J, Hamers FF, Callens S, Lucas R, Barros H, Ruutel K, et al. HIV testing practices as reported by HIV-infected patients in four European countries. AIDS Care. 2014 Apr;26(4):487-96.

(5) Prestage G, Brown G, Keen P. Barriers to HIV testing among Australian gay men. Sex Health. 2012 Nov;9(5):453-8. 
(6) Schwartz SL, Block RG, Schafer SD. Oregon patients with HIV infection who experience delayed diagnosis. AIDS Care. 2014;26(9):1171-7.

(7) Schwarcz S, Richards TA, Frank H, Wenzel C, Hsu LC, Chin CS, et al. Identifying barriers to HIV testing: Personal and contextual factors associated with late HIV testing. AIDS Care. 2011 Jul;23(7):892-900.

(8) Mills CW, Sabharwal CJ, Udeagu C, Bocour A, Bodach S, Shepard C, et al. Barriers to HIV testing among HIVIAIDS concurrently diagnosed persons in New York City. Sex Transm Dis. 2011 Aug;38(8):715-21.

(9) White BL, Walsh J, Rayasam S, Pathman DE, Adimora AA, Golin CE. What makes me screen for HIV? Perceived barriers and facilitators to conducting recommended routine HIV testing among primary care physicians in the southeastern United States. J Int Assoc Provid AIDS Care. 2015 Mar-Apr;14(2):127-35.

(10) Brennan MB, Kolehmainen C, Barocas J, Isaac C, Crnich CJ, Sosman JM. Barriers and facilitators of universal HIV screening among internal medicine residents. WMJ 2013 Oct;112(5):199-205.

(11) Sison N, Yolken A, Poceta J, Mena L, Chan PA, Barnes A, et al. Healthcare provider attitudes, practices, and recommendations for enhancing routine HIV testing and linkage to care in the Mississippi Delta region. AIDS Patient Care STDS. 2013 Sep;27(9):511-7.

(12) Shirreffs A, Lee DP, Henry J, Golden MR, Stekler JD. Understanding barriers to routine HIV screening: Knowledge, attitudes, and practices of healthcare providers in King County, Washington. PLoS ONE 2012 Sep 6;7(9):e44417.

(13) Simmons EM, Brown MJ, Sly K, Ma M, Sutton M, McLellan-Lemal E. Barriers and facilitators to HIV testing in primary care among health care providers. J Natl Med Assoc. 2011 May;103(5):432-8.

(14) Hallmark CJ, Skillicorn J, Giordano TP, Davila JA, McNeese M, Rocha N, et al. HIV testing implementation in two urban cities: Practice, policy, and perceived barriers. PLoS ONE. 2014 Oct 13;9(10):e110010.

(15) Berkenblit GV, Sosman JM, Bass M, Gebrekristos HT, Cofrancesco J Jr, Sullivan LE, et al. Factors affecting clinician educator encouragement of routine HIV testing among trainees. J Gen Intern Med. 2012 Jul;27(7):839-44.

(16) Stefan MS, Blackwell JM, Crawford KM, Martinez J, Wu Sung S, Holliday SA, et al. Patients' attitudes toward and factors predictive of human immunodeficiency virus testing of academic medical clinics. Am J Med Sci. 2010 Oct;340(4):264-7.

(17) Hudson AL, Heilemann MSV, Rodriguez M. Missed opportunities for universal HIV screening in primary care clinics. J Clin Med Res. 2012 Aug;4(4):242-50.

(18) Bogart LM, Howerton D, Lange J, Setodji CM, Becker K, Klein DJ, et Provider-related barriers to rapid HIV testing in U.S. urban non-profit community clinics, community-based organizations (CBOs) and hospitals. AIDS Behav. 2010 Jun;14(3):697-707.

(19) Johnson CV, Mimiaga MJ, Reisner SL, VanDerwarker R, Mayer KH. Barriers and facilitators to routine HIV testing: Peceptions from Massachusetts Community Health Center personnel. AIDS Patient Care STDS 2011 Nov;25(11):647-55.

(20) Mimiaga MJ, Johnson CV, Reisner SL, VanDerwarker R, Mayer KH. Barriers to routine HIV testing among Massachusetts Community Health Center personnel. Public Health Rep. 2011 Sep-Oct;126(5):643-52.

(21) Myers JJ, Koester KA, Dufour MS. Barriers and facilitators to enhancing HIV testing in publicly funded primary care clinics: Findings from San Francisco. AIDS Educ Prev. 2011 Jun;23(3 Suppl):84-95.

(22) Centers for Disease Control and Prevention (CDC). HIV Testing Trends in the United States, 2000-2011. Atlanta, GA: U.S. Department of Health and Human Services, CDC; 2013 Jan.

(23) Korthius TP, Berkenblit GV, Sullivan LE, Cofrancesco J, Cook RL, Bass M, et al. General internists' beliefs, behaviors, and perceived barriers to routine HIV screening in primary care. AIDS Educ Prev. 2011 Jun;23(3 Suppl):70-83.

(24) Arbelaez C, Wright EA, Losina E, Millen JC, Kimmel S, Dooley M, et al. Emergency provider attitudes and barriers to universal HIV testing in the emergency department. J Emerg Med. 2012 Jan;42(1):7-14. Lorenc T, Marrero-Guillamón I, Llewellyn A, Aggleton P, Cooper C, Lehmann A, et al. HIV testing among men who have sex with men (MSM): Systematic review of qualitative evidence. Health Educ Res. 2011 Oct;26(5):834-46.

(26) Wertheimer S, Canadian AIDS Society. Women and HIV Testing in Canada: Barriers and Recommendations as Identified by Service Providers: A Summary of Key Research Findings. Ottawa, ON: Canadian AIDS Society; 2011.(Disponible en français : http://www.cdnaids.ca/home.nsf/pages/les-femmes-et-le-depistage-du-vih-au-canada)

(27) Iqbal S,De Souza LR, Yudin MH. Acceptability, predictors and attitudes of Canadian women in labour toward point-of-care HIV testing at a single labour and delivery unit. Can J Infect Dis Med Microbiol. 2014 Jul;25(4):201-6.

(28) DeMarco RF, Gallagher D, Bradley-Springer L, Jones SG, Visk J. Recommendations and reality: Perceived patient, provider, and policy barriers to implementing routine HIV screening and proposed solutions. Nurs Outlook. 2012 Mar-Apr;60(2):72-80.

(29) Glasman LR, Weinhardt LS, Difranceisco W, Hackl KL. Intentions to seek and accept an HIV test among men of Mexican descent in the midwestern USA. AIDS Care. 2010 Jun;22(6):718-28. 
(30) Hyden C, Allegrante JP, Cohall AT. HIV testing sites' communication about adolescent confidentiality: Potential barriers and facilitators to testing. Health Promot Pract. 2014 Mar;15(2):173-80.

(31) Trepka MJ, Fennie KP, Sheehan DM, Lutfi K, Maddox L, Lieb S. Late HIV diagnosis: Differences by rural/urban residence, Florida, 2007-2011. AIDS Patient Care STDS. 2014 Apr;28(4):188-97.

(32) Sawleshwarkar S, Harrison C, Britt H, Mindel A. Determinants of HIV testing. Sex Transm Infect. 2011 Aug;87(5):426-32.

(33) Haines CJ, Uwazuoke K, Zussman B, Parrino T, Laguerre R, Foster J. Pediatric emergency department-based rapid HIV testing: Adolescent attitudes and preferences. Pediatr Emerg Care. 2011 Jan;27(1):13-6.

(34) Yazdanpanah Y, Lange J, Gerstoft J, Cairns G. Earlier testing for HIV-How do we prevent late presentation? Antivir Ther. 2010;15(Supp 1):17-24.

(35) European Centre for Disease Prevention and Control (ECDC). HIV testing: Increasing uptake and effectiveness in the European Union. In brief. Stockholm: ECDC; 2010.

(36) Knussen C, Flowers P, McDaid LM. Factors associated with recency of HIV testing amongst men residing in Scotland who have sex with men. AIDS Care. 2014;26(3):297-303.

(37) Adam PC, de Wit JB, Bourne CP, Knox D, Purchas J. Promoting regular testing: An examination of HIV and STI testing routines and associated socio-demographic, behavioral and social-cognitive factors among men who have sex with men in New South Wales, Australia. AIDS Behav. 2014 May;18(5):921-32. 
Annexe 1 : Résumé des études sur les obstacles au dépistage du VIH

\begin{tabular}{|c|c|c|c|c|c|}
\hline $\begin{array}{l}\text { Auteur } \\
\text { (année) }\end{array}$ & $\begin{array}{l}\text { Pays/ } \\
\text { région }\end{array}$ & $\begin{array}{c}\text { Question(s)/ } \\
\text { objectif de l'étude }\end{array}$ & Méthodologie & Population & $\begin{array}{c}\text { Principales conclusions/ } \\
\text { obstacles repérés }\end{array}$ \\
\hline $\begin{array}{l}\text { Lorenc } \\
\text { et al. (2011) } \\
(25)\end{array}$ & Angleterre & $\begin{array}{l}\text { Données qualitatives } \\
\text { liées à la perception } \\
\text { et à l'attitude des } \\
\text { hommes ayant des } \\
\text { relations sexuelles } \\
\text { avec d'autres } \\
\text { hommes à l'égard du } \\
\text { dépistage du VIH }\end{array}$ & $\begin{array}{l}\text { Examen } \\
\text { systématique }\end{array}$ & $\begin{array}{l}\text { Hommes } \\
\text { ayant des } \\
\text { relations } \\
\text { sexuelles avec } \\
\text { d'autres } \\
\text { hommes }\end{array}$ & $\begin{array}{l}\text { Obstacles: } \\
\text { - Peur des conséquences de résultats positifs } \\
\text { - Impression de stigmatisation de la part des } \\
\text { autres hommes gais ou d'une population plus } \\
\text { large }\end{array}$ \\
\hline $\begin{array}{l}\text { Deblonde et } \\
\text { al. (2010) (3) }\end{array}$ & $\begin{array}{l}\text { Onze pays } \\
\text { d'Europe, } \\
\text { le Moyen } \\
\text { Orient et } \\
\text { la Russie }\end{array}$ & $\begin{array}{l}\text { Obstacles au } \\
\text { dépistage du VIH }\end{array}$ & $\begin{array}{l}\text { Examen } \\
\text { systématique }\end{array}$ & Divers & $\begin{array}{l}\text { Pour les patients: } \\
\text { - Peur (résultats positifs, incapacité à faire face } \\
\text { aux résultats, stigmatisation) } \\
\text { - Impression de certains patients que le risque } \\
\text { - } \text { - Craint faible } \\
\text { - } \text { Ignorance quant aux sites où subir le test de } \\
\text { dépistage } \\
\text { Pour les fournisseurs de soins de santé : } \\
\text { - Malaise à l'idée de proposer un test de } \\
\text { - } \text { dépistage du VIH } \\
\text { - Réticence à l'idée de proposer le dépistage } \\
\text { - Manque de ressources } \\
\text { - Manque de politiques universelles }\end{array}$ \\
\hline $\begin{array}{l}\text { Centers for } \\
\text { Disease } \\
\text { Control and } \\
\text { Prevention } \\
(2013)(22)\end{array}$ & États-Unis & $\begin{array}{l}\text { Examen des } \\
\text { tendances en matière } \\
\text { de dépistage parmi } \\
\text { différents groupes - } \\
\text { discussion sur les } \\
\text { obstacles dans la } \\
\text { section des } \\
\text { commentaires }\end{array}$ & Examen & Divers & $\begin{array}{l}\text { Pour les patients : } \\
\text { - Peur/inquiétudes au sujet de la stigmatisation } \\
\text { et de la discrimination d'après les résultats du } \\
\text { test } \\
\text { - Coûts des tests de dépistage } \\
\text { Pour les fournisseurs de soins de santé : } \\
\text { - Perception que le dépistage en fonction des } \\
\text { facteurs de risque est plus efficace que le } \\
\text { dépistage de routine } \\
\text { - Inquiétude au sujet du remboursement du } \\
\text { dépistage } \\
\text { - Longue procédure liée au consentement } \\
\text { éclairé et au counseling prétest } \\
\text { - Pas de certification pour offrir du counseling } \\
\text { - Dur le VIH } \\
\text { Dépistage du VIH pas offert dans } \\
\text { l'établissement du fournisseur de soins de } \\
\text { santé }\end{array}$ \\
\hline $\begin{array}{l}\text { DeMarco et } \\
\text { al. (2012) } \\
(28)\end{array}$ & États-Unis & $\begin{array}{l}\text { Obstacles au respect } \\
\text { des } \\
\text { recommandations du } \\
\text { Centers for Disease } \\
\text { Control and } \\
\text { Prevention sur le } \\
\text { dépistage du VIH de } \\
\text { routine }\end{array}$ & Examen & Divers & $\begin{array}{l}\text { Pour les patients : } \\
\text { - Craintes de la stigmatisation, d'être } \\
\text { discriminé ou jugé pour avoir subi le test } \\
\text { - Manque de risque perçu } \\
\text { - Difficulté d'accès } \\
\text { - Inquiétudes à l'égard de la } \\
\text { confidentialité/anonymat } \\
\text { Pour les fournisseurs de soins de santé : } \\
\text { - Manque de temps pour mettre en œuvre les } \\
\text { - } \text { Improcédures de dépistage de routine } \\
\text { - } \text { Incollectivité } \\
\text { conseiller le risque est limité dans la } \\
\end{array}$ \\
\hline
\end{tabular}




\begin{tabular}{|c|c|c|c|c|c|}
\hline $\begin{array}{l}\text { Auteur } \\
\text { (année) }\end{array}$ & $\begin{array}{l}\text { Pays/ } \\
\text { région }\end{array}$ & $\begin{array}{c}\text { Question(s)/ } \\
\text { objectif de l'étude }\end{array}$ & Méthodologie & Population & Principales conclusions/obstacles repérés \\
\hline $\begin{array}{l}\text { Wertheimer } \\
(2011)(26)\end{array}$ & Canada & $\begin{array}{l}\text { Obstacles auxquels les } \\
\text { femmes font face pour } \\
\text { ce qui est du dépistage } \\
\text { du VIH }\end{array}$ & Examen & Femmes & $\begin{array}{l}\text { Pour les patientes: } \\
\text { - Peur d'être jugées par la collectivité ou les } \\
\text { fournisseurs de soins de santé } \\
\text { - Peur du manque de confidentialité ou de } \\
\text { rencontrer des gens qu'elles connaissent au } \\
\text { cabinet } \\
\text { - Accès (p. ex. le test n'est pas anonyme dans } \\
\text { toutes les provinces) } \\
\text { Pour les fournisseurs de soins de santé : } \\
\text { - Supposition que la patiente présente un } \\
\text { risque faible }\end{array}$ \\
\hline $\begin{array}{l}\text { Yazdanpanah } \\
\text { et al. (2010) } \\
(34)\end{array}$ & $\begin{array}{l}24 \text { pays } \\
\text { d'Europe } \\
\text { et la } \\
\text { Russie }\end{array}$ & $\begin{array}{l}\text { Obstacles au dépistage } \\
\text { précoce : Raisons pour } \\
\text { lesquelles les patients } \\
\text { se présentent tard } \\
\text { Façon de surmonter } \\
\text { les obstacles }\end{array}$ & Examen & $\begin{array}{l}\text { Plusieurs études } \\
\text { sur différentes } \\
\text { populations }\end{array}$ & $\begin{array}{l}\text { Pour les patients: } \\
\text { - Déni du facteur de risque } \\
\text { - Manque de connaissances au sujet des } \\
\text { options de traitement pour les personnes } \\
\text { séropositives } \\
\text { - Peur des conséquences d'un test positif } \\
\text { (principalement des inquiétudes liées à la } \\
\text { discrimination et à l'exclusion) } \\
\text { Pour les fournisseurs de soins de santé : } \\
\text { - Exigences liées à la procédure relative au } \\
\text { - } \text { consentement et au counseling prétest } \\
\text { - Briorités en concurrence }\end{array}$ \\
\hline $\begin{array}{l}\text { Deblonde et } \\
\text { al. (2014) (4) }\end{array}$ & $\begin{array}{l}\text { Belgique, } \\
\text { Estonie, } \\
\text { Finlande, } \\
\text { Portugal }\end{array}$ & $\begin{array}{l}\text { Raisons d'avoir subi le } \\
\text { test ou raisons de ne } \\
\text { pas avoir subi de test } \\
\text { de dépistage du VIH } \\
\text { auparavant }\end{array}$ & Sondage & $\begin{array}{l}\text { Patients ayant } \\
\text { été } \\
\text { diagnostiqués } \\
\text { séropositifs } \\
\text { récemment } \\
(72 \% \\
\text { d'hommes) }\end{array}$ & $\begin{array}{l}\text { Raisons de ne pas avoir subi le test de } \\
\text { - } \text { dépistage : } \\
\text { Impression que le risque était faible citée le } \\
\text { - } \text { Le patient ne se sentait pas malade } \\
\text { - Peur de l'infection au VIH } \\
\text { - Peur de la stigmatisation et de la } \\
\text { - } \text { discrimination } \\
\text { - } \text { Peur du non-respect de la confidentialité } \\
\text { - Obstacles pratiques et financiers }\end{array}$ \\
\hline $\begin{array}{l}\text { Hallmark et } \\
\text { al. (2014) } \\
(14)\end{array}$ & États-Unis & $\begin{array}{l}\text { Sur une échelle } \\
\text { de } 1 \text { à } 5 \text {, dans quelle } \\
\text { mesure pensez-vous } \\
\text { que certains facteurs } \\
\text { constituent un } \\
\text { obstacle? }\end{array}$ & Sondage & $\begin{array}{l}\text { Coordonnateurs } \\
\text { du dépistage du } \\
\text { VIH, directeurs } \\
\text { de programmes, } \\
\text { infirmières } \\
\text { gestionnaires, } \\
\text { directeurs de } \\
\text { laboratoires } \\
\text { dans divers } \\
\text { environnements }\end{array}$ & $\begin{array}{l}\text { Taux le plus haut/sélection la plus fréquente: } \\
\text { - Manque de financement pour le dépistage } \\
\text { - Gène/refus du patient } \\
\text { - Le VIH n'est pas un problème pour la } \\
\text { population de clients } \\
\text { - Temps du personnel limité pour offrir le } \\
\text { dépistage } \\
\text { - Volume de personnel limité pour offrir le } \\
\text { dépistage }\end{array}$ \\
\hline $\begin{array}{l}\text { Iqbal, } \\
\text { DeSouza et } \\
\text { Yudin (2014) } \\
(27)\end{array}$ & Canada & $\begin{array}{l}\text { Consentement au } \\
\text { dépistage (oui/non) et } \\
\text { attitude à l'égard du } \\
\text { dépistage pendant } \\
\text { l'accouchement } \\
\text { Différences entre celles } \\
\text { qui acceptent et celles } \\
\text { qui refusent }\end{array}$ & Sondage & $\begin{array}{l}\text { Femmes } \\
\text { enceintes } \\
\text { séronégatives } \\
\text { en travail qui se } \\
\text { présentent à } \\
\text { l'hôpital }\end{array}$ & $\begin{array}{l}\text { Raisons principales de refus : } \\
\text { - Je ne veux pas savoir } \\
\text { - Contractions trop douloureuses } \\
\text { - Peur de la douleur due au test } \\
\text { - Peur du non-respect de la confidentialité } \\
\text { - Peur de la réaction de la collectivité ou de la } \\
\quad \text { famille du conjoint }\end{array}$ \\
\hline
\end{tabular}




\begin{tabular}{|c|c|c|c|c|c|}
\hline $\begin{array}{l}\text { Auteur } \\
\text { (année) }\end{array}$ & $\begin{array}{l}\text { Pays/ } \\
\text { région }\end{array}$ & $\begin{array}{c}\text { Question(s)/ } \\
\text { objectif de l'étude }\end{array}$ & Méthodologie & Population & Principales conclusions/obstacles repérés \\
\hline $\begin{array}{l}\text { Prestage, } \\
\text { Brown et } \\
\text { Keen }(2012) \\
(5)\end{array}$ & Australie & $\begin{array}{l}\text { Raison du report ou de } \\
\text { refus du test de } \\
\text { dépistage du VIH }\end{array}$ & Sondage & $\begin{array}{l}\text { Hommes } \\
\text { séronégatifs }\end{array}$ & $\begin{array}{l}\text { Obstacles communément sélectionnés } \\
\text { - Je n'ai rien fait de risqué }(41,2 \%) \\
\text { - II me faudrait revenir pour chercher les } \\
\text { résultats }(40,3 \%) \\
\text { - Je n'ai pas le temps }(25,4 \%) \\
\text { - Je n'ai pas changé de partenaire }(19,8 \%) \\
\text { - Je n'ai pas eu de maladie ou de symptômes } \\
\text { qui me donnent des raisons de m'inquiéter } \\
\text { - Il est difficile d'obtenir un rendez-vous } \\
\text { ( } 19,2 \%) \\
\text { - J'ai peur qu'on puisse me dire que j'ai } \\
\text { contracté le VIH (14,1\%) }\end{array}$ \\
\hline $\begin{array}{l}\text { Arbelaez et } \\
\text { al. (2012) } \\
(24)\end{array}$ & États-Unis & \begin{tabular}{|l|} 
Obstacles à la mise en \\
œuvre de test de \\
dépistage du VIH dans \\
les services d'urgences
\end{tabular} & Sondage & $\begin{array}{l}\text { Fournisseurs de } \\
\text { soins de santé } \\
\text { dans les services } \\
\text { d'urgences }\end{array}$ & $\begin{array}{l}\text { Obstacles les plus couramment cités : } \\
\text { - Manque de temps }(61 \%) \\
\text { - Manque de ressources }(60 \%) \\
\text { - Inquiétudes quant au suivi }(59 \%)\end{array}$ \\
\hline $\begin{array}{l}\text { Shirreffs et } \\
\text { al. (2012) } \\
(12)\end{array}$ & États-Unis & \begin{tabular}{|l|} 
Est d'accord/en \\
désaccord avec les \\
obstacles couramment \\
mentionnés
\end{tabular} & Sondage & $\begin{array}{l}\text { Fournisseurs de } \\
\text { soins de santé }\end{array}$ & $\begin{array}{l}\text { - Patients à faible risque }(57 \%) \\
\text { - Temps supplémentaire accordé en } \\
\text { counseling }(31 \%) \\
\text { - Procédure relative au consentement }(22 \%) \\
\text { - } \text { Questions juridiques }(20 \%) \\
\text { - } \text { Barrière de la langue }(19 \%) \\
\text { - } \text { Autres inquiétudes liées aux contraintes de } \\
\text { - } \text { temps }(17 \%) \\
\text { - Inquiétudes liées au remboursement }(13 \%)\end{array}$ \\
\hline $\begin{array}{l}\text { Berkenblit et } \\
\text { al. }(2012) \\
(15)\end{array}$ & États-Unis & $\begin{array}{l}\text { Les stagiaires sont-ils } \\
\text { encouragés à réaliser } \\
\text { un test de dépistage du } \\
\text { VIH de routine } \\
\text { (oui/non)? Si tel n'est } \\
\text { pas le cas, pourquoi } \\
\text { (choix parmi plusieurs } \\
\text { propositions)? }\end{array}$ & Sondage & $\begin{array}{l}\text { Éducateurs } \\
\text { cliniques de la } \\
\text { Society of } \\
\text { General Internal } \\
\text { Medicine }\end{array}$ & $\begin{array}{l}\text { Raisons de ne pas encourager le test de } \\
\text { dépistage de routine : } \\
\text { - Impression que la prévalence est faible dans } \\
\text { la région } \\
\text { - Sujets d'enseignement plus importants } \\
\text { - Environnement trop occupé en clinique } \\
\text { - Connaissances insuffisantes en matière de } \\
\text { - } \text { recommandations } \\
\text { - Désaccord avec les recommandations }\end{array}$ \\
\hline $\begin{array}{l}\text { Korthius et } \\
\text { al. (2011) } \\
(23)\end{array}$ & États-Unis & \begin{tabular}{|l|} 
Est d'accord/en \\
désaccord avec les \\
obstacles couramment \\
mentionnés
\end{tabular} & Sondage & $\begin{array}{l}\text { Spécialistes de } \\
\text { médecine interne }\end{array}$ & $\begin{array}{l}\text { - Priorités concurrentes pendant les visites } \\
(79 \%) \\
\text { - Temps }(64 \%) \\
\text { - Réticence des patients }(64 \%) \\
\text { - Exigences en matière de consentement } \\
(49 \%)\end{array}$ \\
\hline $\begin{array}{l}\text { Mimiaga et } \\
\text { al. }(2011) \\
(20)\end{array}$ & États-Unis & $\begin{array}{l}\text { Obstacles à la mise en } \\
\text { place d'un dépistage } \\
\text { du VIH au site }\end{array}$ & Sondage & $\begin{array}{l}\text { Administrateurs } \\
\text { principaux, } \\
\text { directeurs } \\
\text { médicaux et } \\
\text { fournisseurs de } \\
\text { soins de santé } \\
\text { de centres } \\
\text { communautaires }\end{array}$ & 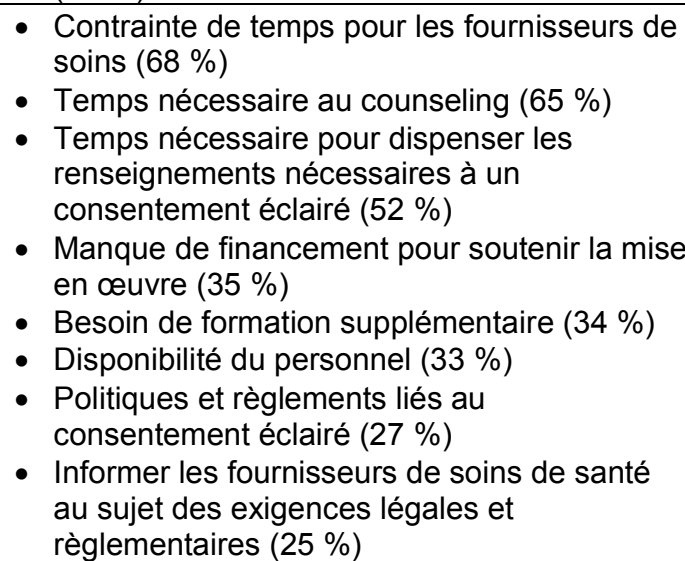 \\
\hline
\end{tabular}




\begin{tabular}{|c|c|c|c|c|c|}
\hline $\begin{array}{l}\text { Auteur } \\
\text { (année) }\end{array}$ & $\begin{array}{l}\text { Pays/ } \\
\text { région }\end{array}$ & $\begin{array}{c}\text { Question(s)/ } \\
\text { objectif de l'étude }\end{array}$ & Méthodologie & Population & $\begin{array}{c}\text { Principales conclusions/ } \\
\text { obstacles repérés }\end{array}$ \\
\hline $\begin{array}{l}\text { Glasman et } \\
\text { al. }(2010) \\
(29)\end{array}$ & États-Unis & $\begin{array}{l}\text { Facteurs qui } \\
\text { influencent les gens à } \\
\text { demander/accepter un } \\
\text { test de dépistage du } \\
\text { VIH }\end{array}$ & Sondage & $\begin{array}{l}\text { Hommes } \\
\text { hétérosexuels } \\
\text { d'origine } \\
\text { mexicaine }\end{array}$ & $\begin{array}{l}\text { Moins susceptibles de demander un test si : } \\
\text { - Ils s'attendent à des conséquences } \\
\text { négatives : p. ex. stigmatisation, fatalisme } \\
(\mathrm{RC}=0,40)\end{array}$ \\
\hline $\begin{array}{l}\text { Bogart et al. } \\
(2010)(18)\end{array}$ & États-Unis & $\begin{array}{l}\text { Obstacles à } \\
\text { l'administration d'un } \\
\text { test de dépistage } \\
\text { rapide du VIH }\end{array}$ & Sondage & $\begin{array}{l}\text { Personnel de } \\
\text { laboratoire et } \\
\text { des services } \\
\text { d'hôpitaux } \\
\text { Personnel de } \\
\text { cliniques et } \\
\text { d'organisations } \\
\text { communautaires }\end{array}$ & $\begin{array}{l}\text { Pour les laboratoires: } \\
\text { - } \quad \text { Difficulté à apprendre les procédures et la } \\
\text { - } \text { règlementation fédérale et des États } \\
\text { - } \quad \text { Manque de formation du personnel } \\
\text { - } \quad \text { Possibilité de faux résultats positifs } \\
\text { Pour les services hospitaliers : } \\
\text { - } \quad \text { Trop de lois et règlements fédéraux et des } \\
\text { États } \\
\text { - Difficulté à intégrer le counseling aux autres } \\
\text { - } \quad \text { services } \\
\text { - } \quad \text { sessiculté à s'occuper du counseling dans une } \\
\text { - } \quad \text { Difficulté à expliquer le test de dépistage } \\
\text { rapide aux patients dont les capacités } \\
\text { linguistiques sont faibles } \\
\text { Cliniques et organisations communautaires : } \\
\text { - Manque de ressources/d'espace pour mettre } \\
\text { - } \quad \text { Manque de personnel } \\
\text { - Règlementation difficile à comprendre } \\
\text { Personnel incertain d'où diriger les patients } \\
\text { pour recevoir des soins si les résultats sont } \\
\text { positifs }\end{array}$ \\
\hline $\begin{array}{l}\text { White et al. } \\
(2014)(9)\end{array}$ & États-Unis & $\begin{array}{l}\text { Perception des } \\
\text { obstacles et des } \\
\text { facteurs favorables à la } \\
\text { mise en œuvre d'un } \\
\text { dépistage du VIH de } \\
\text { routine d'après les } \\
\text { médecins de premier } \\
\text { recours }\end{array}$ & Entrevue & $\begin{array}{l}\text { Médecin de } \\
\text { premier recours }\end{array}$ & $\begin{array}{l}\text { Pour les patients : } \\
\text { - } \quad \text { Impression que le risque d'infection par le } \\
\text { VIH est faible } \\
\text { - } \quad \text { Crainte de la stigmatisation } \\
\text { - Refus du test de dépistage du VIH } \\
\text { Pour les fournisseurs de soins de santé : } \\
\text { - Stigmatisation liée au VIH/sida } \\
\text { - Communautés conservatrices du point de } \\
\text { - } \quad \text { Mae social } \\
\text { - Emque de confidentialité } \\
\text { - Contrainte de temps et priorités cliniques } \\
\text { - } \quad \text { Pas de remboursement universel }\end{array}$ \\
\hline $\begin{array}{l}\text { Schwartz, } \\
\text { Block et } \\
\text { Schafer } \\
(2014)(6)\end{array}$ & États-Unis & $\begin{array}{l}\text { Facteurs menant ou } \\
\text { associés à un } \\
\text { diagnostic tardif }\end{array}$ & Entrevue & $\begin{array}{l}\text { Patients ayant } \\
\text { reçu un } \\
\text { diagnostic tardif } \\
\text { du VIH (par } \\
\text { définition, } \\
\text { personnes } \\
\text { ayant } \\
\text { développé le } \\
\text { sida dans les } \\
12 \text { mois après } \\
\text { avoir été } \\
\text { diagnostiquées } \\
\text { séropositive) }\end{array}$ & $\begin{array}{l}\text { Thèmes récurrents lors des entrevues: } \\
\text { - Impression que le risque d'infection par le } \\
\text { VIH est fiable } \\
\text { - Occasion ratée de subir le test alors que le } \\
\text { patient recevait des soins pour une maladie } \\
\text { - Le médecin ne propose pas le dépistage, } \\
\text { car le patient ne correspond pas aux } \\
\text { catégories à risque traditionnelles ou parce } \\
\text { qu'il n'a pas révélé ses facteurs de risque } \\
\text { - Dépistage recommandé, mais pas réalisé } \\
\text { soit pour des raisons financières (p. ex. pas } \\
\text { d'assurance), soit à cause de la peur des } \\
\text { résultats }\end{array}$ \\
\hline
\end{tabular}




\begin{tabular}{|c|c|c|c|c|c|}
\hline $\begin{array}{l}\text { Auteur } \\
\text { (année) }\end{array}$ & $\begin{array}{l}\text { Pays/ } \\
\text { région }\end{array}$ & $\begin{array}{c}\text { Question(s)/ } \\
\text { objectif de l'étude }\end{array}$ & Méthodologie & Population & $\begin{array}{l}\text { Principales conclusions/ } \\
\text { obstacles repérés }\end{array}$ \\
\hline $\begin{array}{l}\text { Brennan et } \\
\text { al. (2013) } \\
(10)\end{array}$ & États-Unis & $\begin{array}{l}\text { Obstacles et facteurs } \\
\text { favorables à l'adoption } \\
\text { d'un dépistage du VIH } \\
\text { universel dans un } \\
\text { contexte de faible } \\
\text { prévalence }\end{array}$ & Entrevue & $\begin{array}{l}\text { Résidents de } \\
\text { médecine interne }\end{array}$ & $\begin{array}{l}\text { Les médecins trouvent qu'il est difficile de } \\
\text { discuter du dépistage du VIH à cause de : } \\
\text { - la stigmatisation entourant le VIH } \\
\text { - la perception que les patients sont à faible } \\
\text { risque }\end{array}$ \\
\hline $\begin{array}{l}\text { Sison et al. } \\
(2013)(11)\end{array}$ & États-Unis & $\begin{array}{l}\text { Attitude et pratiques } \\
\text { des médecins à l'égard } \\
\text { du dépistage du VIH et } \\
\text { lien avec les soins }\end{array}$ & Entrevue & $\begin{array}{l}\text { Médecins de } \\
\text { premier recours } \\
\text { et spécialistes } \\
\text { des maladies } \\
\text { infectieuses }\end{array}$ & $\begin{array}{l}\text { Pour les patients : } \\
\text { - Crainte de la stigmatisation } \\
\text { - Manque de fournisseurs de soins pour le } \\
\text { VIH } \\
\text { - Long déplacement pour recevoir des } \\
\text { services de soins/traitement } \\
\text { Pour les fournisseurs de soins de santé : } \\
\text { - Pas de remboursement } \\
\text { - Manque de connaissances au sujet de lois } \\
\text { - de l'État sur le consentement } \\
\text { Patients qui perçoivent leur risque d'infection } \\
\text { - Dar le VIH comme étant faible } \\
\text { des fournisseurs de soins }\end{array}$ \\
\hline $\begin{array}{l}\text { Hyden, } \\
\text { Allegrante et } \\
\text { Cohall } \\
(2013)(30)\end{array}$ & États-Unis & $\begin{array}{l}\text { Obstacles rencontrés } \\
\text { par les adolescents } \\
\text { quand ils demandent } \\
\text { un dépistage du VIH }\end{array}$ & Entrevue & $\begin{array}{l}\text { Représentants } \\
\text { des sites de } \\
\text { dépistage du VIH }\end{array}$ & $\begin{array}{l}\text { - } 12 \% \text { des agences interrogées offrent un } \\
\text { dépistage hors des heures normales de } \\
\text { bureau, soit de } 8 \text { h } 30 \text { à } 17 \mathrm{~h} \text { du lundi au } \\
\text { vendredi } \\
\text { - } 23 \% \text { offrent un dépistage uniquement entre } \\
9 \mathrm{~h} \text { et } 15 \text { h en semaine, soit quand la plupart } \\
\text { des adolescents sont à l'école } \\
\text { - } 17 \% \text { des personnes n'avaient pas la bonne } \\
\text { information, étaient incertaines ou ne } \\
\text { savaient pas si la permission des parents } \\
\text { était nécessaire pour qu'un jeune de } 15 \text { ans } \\
\text { subisse un test de dépistage } \\
\text { - } 14 \% \text { ont répondu de manière incorrecte ou } \\
\text { ne savaient pas répondre quand on leur } \\
\text { demandait si les parents d'un adolescent } \\
\text { pouvaient découvrir les résultats des tests } \\
\text { d'un adolescent }\end{array}$ \\
\hline $\begin{array}{l}\text { Hudson, } \\
\text { Heilemann } \\
\text { et Rodriguez } \\
(2012)(17)\end{array}$ & États-Unis & $\begin{array}{l}\text { Perspectives et } \\
\text { expériences des } \\
\text { fournisseurs de soins } \\
\text { primaires à l'égard des } \\
\text { obstacles et des } \\
\text { facteurs favorables à } \\
\text { l'offre d'un counseling } \\
\text { et d'un test volontaire } \\
\text { du VIH à tous les } \\
\text { patients âgés de } 13 \text { à } \\
64 \text { ans dans le cadre } \\
\text { d'un dépistage annuel }\end{array}$ & Entrevue & $\begin{array}{l}\text { Fournisseurs de } \\
\text { soins primaires } \\
\text { (c.-à-d. } \\
\text { médecine } \\
\text { familiale, } \\
\text { médecine interne } \\
\text { et pédiatrique) }\end{array}$ & $\begin{array}{l}\text { - Sentiment que les patients perdront la } \\
\text { confiance acquise, se sentiront stigmatisés } \\
\text { et obligés de subir le test } \\
\text { - Contrainte de temps liée à l'obtention du } \\
\text { consentement et aux procédures de } \\
\text { counseling } \\
\text { - Peur au sujet de la capacité à faire face en } \\
\text { cas de résultats positifs } \\
\text { - Suppositions concernant la nécessité du } \\
\text { dépistage liées à l'âge du patient et à son } \\
\text { état matrimonial }\end{array}$ \\
\hline $\begin{array}{l}\text { Mills et al. } \\
(2011)(8)\end{array}$ & États-Unis & $\begin{array}{l}\text { Obstacles au } \\
\text { dépistage initial des } \\
\text { personnes } \\
\text { séropositives }\end{array}$ & Entrevue & $\begin{array}{l}\text { Personne } \\
\text { séropositive }\end{array}$ & $\begin{array}{l}\text { Obstacles communément sélectionnés : } \\
\text { - Mesure insuffisante du risque }(69 \%) \\
\text { - Comportement qui les protégeait de la } \\
\text { contraction du VIH (52\%) } \\
\text { - Jamais le test ne leur a été proposé }(42 \%) \\
\text { - Peur que les résultats soient positifs }(23 \%) \\
\text { - Inquiétudes au sujet de la confidentialité } \\
\text { - }(17 \%) \\
\text { Peur de perdre des amis ou des membres } \\
\text { de leur famille si quelqu'un venait à } \\
\text { découvrir qu'ils sont séropositifs (12\%) }\end{array}$ \\
\hline
\end{tabular}




\begin{tabular}{|c|c|c|c|c|c|}
\hline $\begin{array}{l}\text { Auteur } \\
\text { (année) }\end{array}$ & $\begin{array}{l}\text { Pays/ } \\
\text { région }\end{array}$ & $\begin{array}{c}\text { Question(s)/ } \\
\text { objectif de l'étude }\end{array}$ & Méthodologie & Population & Principales conclusions/obstacles repérés \\
\hline $\begin{array}{l}\text { Johnson et } \\
\text { al. (2011) } \\
(19)\end{array}$ & États-Unis & $\begin{array}{l}\text { Obstacles au } \\
\text { dépistage selon les } \\
\text { fournisseurs de soins } \\
\text { de santé }\end{array}$ & Entrevue & \begin{tabular}{|l|} 
Personnel de \\
direction de \\
centres de santé \\
communautaires
\end{tabular} & $\begin{array}{l}\text { - Manque de temps } \\
\text { - Manque de ressources (financières et } \\
\text { humaines) } \\
\text { - Gène à l'égard du sujet (poser des questions } \\
\text { d'ordre sexuel, susciter de la peur chez le } \\
\text { patient) }\end{array}$ \\
\hline $\begin{array}{l}\text { Schwarcz et } \\
\text { al. (2011) (7) }\end{array}$ & États-Unis & $\begin{array}{l}\text { Facteurs qui mènent } \\
\text { à un } \\
\text { dépistage/diagnostic } \\
\text { tardif du VIH }\end{array}$ & Entrevue & \begin{tabular}{|l|} 
Personnes \\
ayant \\
développé le \\
sida dans les \\
12 mois après \\
avoir été \\
diagnostiquées \\
séropositives \\
(hommes à \\
$88,4 \%$ ) \\
\end{tabular} & $\begin{array}{l}\text { - Peur (p. ex. résultats positifs, répercussions } \\
\text { sociales, manque de soutien) }(68 \%) \\
\text { - Mesure insuffisante du risque (34 \%) } \\
\text { - Aucune assurance médicale }\end{array}$ \\
\hline $\begin{array}{l}\text { Simmons et } \\
\text { al. }(2011) \\
(13)\end{array}$ & États-Unis & $\begin{array}{l}\text { Obstacles et facteurs } \\
\text { favorables au test de } \\
\text { dépistage du VIH de } \\
\text { routine }\end{array}$ & Entrevue & $\begin{array}{l}\text { Fournisseurs } \\
\text { de soins de } \\
\text { santé }\end{array}$ & $\begin{array}{l}\text { - Gène à l'idée d'engager la conversation avec } \\
\text { les patients au sujet du VIH } \\
\text { - Absence de documentation destinée aux } \\
\text { patients } \\
\text { - Supposition incorrecte en ce qui a trait aux } \\
\text { risques du patient } \\
\text { - Manque de formation sur le VIH } \\
\text { - Rythme soutenu des visites en cabinet de soins } \\
\text { primaires } \\
\text { - Fardeau financier lié à l'augmentation du } \\
\text { volume de dépistage du VIH } \\
\text { - Peur des patients liée aux résultats } \\
\text { - Inquiétudes à l'égard de la confidentialité } \\
\text { - Disponibilité des traitements insuffisante pour } \\
\text { les cas positifs }\end{array}$ \\
\hline $\begin{array}{l}\text { Myers, } \\
\text { Koester et } \\
\text { Dufour } \\
(2011)(21)\end{array}$ & États-Unis & $\begin{array}{l}\text { Obstacles à la mise } \\
\text { en œuvre et } \\
\text { l'expansion du } \\
\text { dépistage du VIH } \\
\text { Stratégies pour } \\
\text { surmonter ces } \\
\text { obstacles }\end{array}$ & Entrevue & \begin{tabular}{|l|} 
Administrateurs \\
du financement \\
et de la gestion \\
de programmes, \\
directeurs \\
médicaux/ \\
médecins \\
dispensant des \\
soins dans des \\
cliniques
\end{tabular} & $\begin{array}{l}\text { Pour les fournisseurs de soins de santé : } \\
\text { - Manque d'expérience du fournisseur de soins } \\
\text { - Impression que le patient est réticent à subir un } \\
\text { test } \\
\text { - Temps nécessaire pour obtenir le } \\
\text { consentement du patient et lui offrir du } \\
\text { counseling } \\
\text { - Priorités concurrentes pendant les visites } \\
\text { - Manque de conviction quant à l'utilité du } \\
\text { dépistage de tous les patients }\end{array}$ \\
\hline $\begin{array}{l}\text { Trepka et al. } \\
(2014)(31)\end{array}$ & États-Unis & $\begin{array}{l}\text { Facteurs associés au } \\
\text { diagnostic tardif chez } \\
\text { les patients vivants } \\
\text { en milieu rural et en } \\
\text { milieu urbain }\end{array}$ & $\begin{array}{l}\text { Examen de } \\
\text { dossiers } \\
\text { médicaux }\end{array}$ & \begin{tabular}{|l|} 
Les personnes \\
qui reçoivent \\
un diagnostic \\
tardif (ayant \\
développé le \\
sida dans les \\
trois mois \\
après le \\
diagnostic) \\
\end{tabular} & $\begin{array}{l}\text { - Le fait de vivre dans un milieu rural est plus } \\
\text { souvent associé à un diagnostic tardif, après le } \\
\text { contrôle pour l'âge, le sexe, la race/ethnicité, le } \\
\text { mode de transmission du VIH, le pays de } \\
\text { naissance et l'année du diagnostic ( } R C=1,39)\end{array}$ \\
\hline
\end{tabular}


Annexe 2 : Résumé des études sur les facteurs favorables au dépistage du VIH

\begin{tabular}{|c|c|c|c|c|c|}
\hline $\begin{array}{l}\text { Auteur } \\
\text { (année) }\end{array}$ & Pays & $\begin{array}{c}\text { Question(s)/ } \\
\text { objectif de l'étude }\end{array}$ & Méthodologie & Population & $\begin{array}{l}\text { Principales conclusions/ facteurs } \\
\text { favorables repérés }\end{array}$ \\
\hline $\begin{array}{l}\text { Lorenc et al. } \\
\text { (2011) (25) }\end{array}$ & Angleterre & $\begin{array}{l}\text { Données qualitatives } \\
\text { liées à la perception et } \\
\text { à l'attitude des } \\
\text { hommes ayant des } \\
\text { relations sexuelles } \\
\text { avec d'autres hommes } \\
\text { à l'égard du dépistage } \\
\text { du VIH }\end{array}$ & $\begin{array}{l}\text { Examen } \\
\text { systématique }\end{array}$ & $\begin{array}{l}\text { Hommes } \\
\text { ayant des } \\
\text { relations } \\
\text { sexuelles } \\
\text { avec d'autres } \\
\text { hommes }\end{array}$ & $\begin{array}{l}\text { Voici certains motifs de dépistage: } \\
\text { - Incertitude causée par l'ignorance de l'état } \\
\text { sérologique } \\
\text { - Responsabilité à l'égard de soi-même et de son } \\
\text { partenaire }\end{array}$ \\
\hline $\begin{array}{l}\text { Yazdanpanah } \\
\text { et al. (2010) } \\
(34)\end{array}$ & $\begin{array}{l}24 \text { pays } \\
\text { d'Europe } \\
\text { et la } \\
\text { Russie }\end{array}$ & $\begin{array}{l}\text { Obstacles au } \\
\text { dépistage précoce : } \\
\text { Raisons pour } \\
\text { lesquelles les patients } \\
\text { demandent un } \\
\text { dépistage tardif. } \\
\text { Façon de surmonter } \\
\text { les obstacles }\end{array}$ & Examen & $\begin{array}{l}\text { Plusieurs } \\
\text { études sur } \\
\text { différentes } \\
\text { populations }\end{array}$ & $\begin{array}{l}\text { Pour les patients: } \\
\text { - Perception du risque } \\
\text { - Perception des avantages du dépistage }\end{array}$ \\
\hline $\begin{array}{l}\text { Adam et al. } \\
(2014)(37)\end{array}$ & Australie & $\begin{array}{l}\text { Facteurs } \\
\text { sociocognitifs } \\
\text { associés à un } \\
\text { dépistage du VIH de } \\
\text { routine plus efficace }\end{array}$ & Sondage & $\begin{array}{l}\text { Hommes } \\
\text { ayant des } \\
\text { relations } \\
\text { sexuelles } \\
\text { avec d'autres } \\
\text { hommes } \\
\text { séronégatifs } \\
\end{array}$ & $\begin{array}{l}\text { Corrélations avec le dépistage du VIH dans une } \\
\text { analyse multivariée } \\
\text { - Âge } \\
\text { - Connaissances en matière de VIH } \\
\text { - Perception des « avantages » du dépistage } \\
\text { - Attitudes à l'égard du dépistage du VIH }\end{array}$ \\
\hline $\begin{array}{l}\text { Knussen, } \\
\text { Flowers et } \\
\text { McDaid } \\
(2014)(36)\end{array}$ & Écosse & $\begin{array}{l}\text { Facteurs divergeant } \\
\text { entre les personnes } \\
\text { qui ont subi le test de } \\
\text { dépistage du VIH au } \\
\text { cours de l'année, } \\
\text { celles qui l'ont subi il } \\
\text { y a plus d'un an et } \\
\text { celles qui ne l'ont } \\
\text { jamais subi }\end{array}$ & Sondage & $\begin{array}{l}\text { Échantillon de } \\
\text { commodité } \\
\text { d'Écossais } \\
\text { ayant des } \\
\text { relations } \\
\text { sexuelles } \\
\text { avec d'autres } \\
\text { hommes }\end{array}$ & $\begin{array}{l}\text { Personnes qui disent avoir subi le test au cours de } \\
\text { l'année : } \\
\text { - Moins peur d'avoir des résultats positifs } \\
\text { - Plus grande norme de dépistage } \\
\text { Plus susceptibles d'avoir eu : } \\
\text { - des relations sexuelles anales avec au moins } \\
\text { un partenaire pendant l'année (utilisation de } \\
\text { condom) } \\
\text { - entre deux et dix partenaires sexuels (par } \\
\text { opposition à un ou aucun) }\end{array}$ \\
\hline $\begin{array}{l}\text { Deblonde et } \\
\text { al. (2014) (4) }\end{array}$ & $\begin{array}{l}\text { Belgique, } \\
\text { Estonie, } \\
\text { Finlande, } \\
\text { Portugal }\end{array}$ & $\begin{array}{l}\text { Raisons de subir un } \\
\text { test, ou raisons de ne } \\
\text { pas avoir subi de test } \\
\text { de dépistage du VIH } \\
\text { avant d'avoir été } \\
\text { diagnostiqué }\end{array}$ & Sondage & $\begin{array}{l}\text { Patients ayant } \\
\text { récemment } \\
\text { été } \\
\text { diagnostiqués } \\
\text { séropositifs }\end{array}$ & $\begin{array}{l}\text { Raison d'avoir fait la demande de dépistage : } \\
\text { - Inquiétude relative à l'exposition aux risques } \\
\text { - Vérification de son état sérologique } \\
\text { - Le patient se sentait malade }\end{array}$ \\
\hline $\begin{array}{l}\text { Sawleshwarkar } \\
\text { et al. (2011) } \\
(32)\end{array}$ & Australie & $\begin{array}{l}\text { Facteurs associés au } \\
\text { dépistage du VIH } \\
\text { selon les } \\
\text { omnipraticiens }\end{array}$ & Sondage & Omnipraticiens & 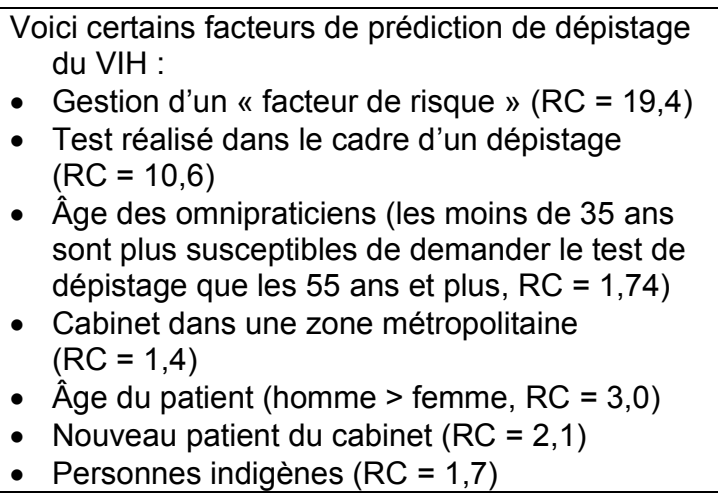 \\
\hline
\end{tabular}




\begin{tabular}{|c|c|c|c|c|c|}
\hline $\begin{array}{l}\text { Auteur } \\
\text { (année) }\end{array}$ & $\begin{array}{l}\text { Pays/ } \\
\text { région }\end{array}$ & $\begin{array}{c}\text { Question(s)/ } \\
\text { objectif de l'étude }\end{array}$ & Méthodologie & Population & Principales conclusions/obstacles repérés \\
\hline $\begin{array}{l}\text { Korthius et al. } \\
(2011)(23)\end{array}$ & États-Unis & $\begin{array}{l}\text { Est d'accord/en } \\
\text { désaccord avec les } \\
\text { obstacles } \\
\text { couramment } \\
\text { mentionnés }\end{array}$ & Sondage & $\begin{array}{l}\text { Spécialistes } \\
\text { de médecine } \\
\text { interne }\end{array}$ & $\begin{array}{l}\text { Facteurs favorables communément sélectionnés : } \\
\text { - Augmentation des coûts associés au } \\
\text { counseling sur le VIH (56\%) } \\
\text { - Avoir à disposition de la documentation à } \\
\text { donner aux patients (53 \%) } \\
\text { - Plus de renseignements sur les exigences en } \\
\text { matière de consentement }\end{array}$ \\
\hline $\begin{array}{l}\text { Haines et al. } \\
(2011)(33)\end{array}$ & États-Unis & $\begin{array}{l}\text { Attitudes et } \\
\text { préférence des } \\
\text { adolescents en } \\
\text { matière de dépistage } \\
\text { du VIH en services } \\
\text { d'urgences, plans } \\
\text { futurs quant au } \\
\text { dépistage, counseling }\end{array}$ & Sondage & $\begin{array}{l}\text { Échantillon de } \\
\text { commodité } \\
\text { d'adolescents } \\
\text { (âgés de } 14 \text { à } \\
21 \text { ans) } \\
\text { subissant un } \\
\text { test de } \\
\text { dépistage } \\
\text { rapide du VIH } \\
\text { avec option } \\
\text { de } \\
\text { participation } \\
\text { en services } \\
\text { d'urgences }\end{array}$ & $\begin{array}{l}\text { - } 80 \% \text { des répondants sont plus susceptibles de } \\
\text { subir un test si une version rapide est } \\
\text { disponible } \\
\text { - } 67 \% \text { sont plus susceptibles de subir le test si } \\
\text { on le leur propose, plutôt que s'ils ont à le } \\
\text { demander } \\
\text { - } 40 \% \text { sont tout à fait d'accord quant à la } \\
\text { préférence d'avoir un conseiller du même sexe } \\
\text { qu'eux }\end{array}$ \\
\hline $\begin{array}{l}\text { Glasman et } \\
\text { al. (2010) (29) }\end{array}$ & États-Unis & $\begin{array}{l}\text { Facteurs qui } \\
\text { influencent les gens à } \\
\text { demander/accepter } \\
\text { un test de dépistage } \\
\text { du VIH gratuit }\end{array}$ & Sondage & $\begin{array}{l}\text { Hommes } \\
\text { hétérosexuels } \\
\text { d'origine } \\
\text { mexicaine }\end{array}$ & $\begin{array}{l}\text { Plus susceptibles de demander/d'accepter un test } \\
\text { si : } \\
\text { - Ils associent le dépistage à des conséquences } \\
\text { positives (p. ex, montrer l'exemple, protéger sa } \\
\text { famille, tranquillité d'esprit) (RC = 4,77 pour } \\
\text { demander le test, } \mathrm{RC}=7,6 \text { pour accepter le } \\
\text { test) } \\
\text { - Ils ont reçu des conseils en matière de } \\
\text { prévention du VIH de la part de leur partenaire } \\
\text { (RC }=2,96 \text { pour demander le test) }\end{array}$ \\
\hline $\begin{array}{l}\text { Stefan et al. } \\
(2010)(16)\end{array}$ & États-Unis & $\begin{array}{l}\text { Corrélations des } \\
\text { déclarations } \\
\text { spontanées } \\
\text { d'antécédents de } \\
\text { dépistage du VIH }\end{array}$ & Sondage & $\begin{array}{l}\text { Patients } \\
\text { adultes dans } \\
\text { des cliniques } \\
\text { universitaires } \\
\text { de médecine } \\
\text { interne }\end{array}$ & $\begin{array}{l}\text { Corrélations à une variable du dépistage du VIH : } \\
\text { - Recommandation du fournisseur de soins } \\
\text { - Demande du patient } \\
\text { - Connaissances sur le VIH } \\
\text { - Patient à l'aise avec son médecin } \\
\text { - Patient afro-américain } \\
\text { - Consommation de drogues de la rue } \\
\text { - Assentiment à l'égard des recommandations du } \\
\text { Fenters for Disease Control and Prevention } \\
\text { Facteurs de prédiction du dépistage du VIH, } \\
\text { modèle de régression à plusieurs variables: } \\
\text { - Patient demandant un dépistage }(\mathrm{RC}=103,3) \\
\text { - Connaissances du patient sur le } \mathrm{VIH}(\mathrm{RC}=1,3)\end{array}$ \\
\hline $\begin{array}{l}\text { Brennan et al. } \\
(2013)(10)\end{array}$ & États-Unis & $\begin{array}{l}\text { Obstacles et facteurs } \\
\text { favorables à } \\
\text { l'adoption d'un } \\
\text { dépistage du VIH } \\
\text { universel dans un } \\
\text { contexte de faible } \\
\text { prévalence }\end{array}$ & Entrevue & $\begin{array}{l}\text { Résidents de } \\
\text { médecine } \\
\text { interne }\end{array}$ & $\begin{array}{l}\text { La majorité des patients étaient particulièrement } \\
\text { réceptifs au dépistage de VIH quand il était } \\
\text { normalisé et qu'on faisant référence à une } \\
\text { autorité compétente (p. ex. Centers for Disease } \\
\text { Control and Prevention) }\end{array}$ \\
\hline $\begin{array}{l}\text { Sison et al. } \\
(2013)(11)\end{array}$ & États-Unis & $\begin{array}{l}\text { Attitude et pratiques } \\
\text { des médecins à } \\
\text { l'égard du dépistage } \\
\text { du VIH et lien avec les } \\
\text { soins }\end{array}$ & Entrevue & $\begin{array}{l}\text { Médecins de } \\
\text { premier } \\
\text { recours et } \\
\text { spécialistes } \\
\text { des maladies } \\
\text { infectieuses } \\
\end{array}$ & $\begin{array}{l}\text { Pour les fournisseurs de soins de santé : } \\
\text { - Presque tous les fournisseurs ont expliqué être } \\
\text { prêts à offrir un dépistage de routine s'ils } \\
\text { pouvaient facturer le service }\end{array}$ \\
\hline
\end{tabular}




\begin{tabular}{|c|c|c|c|c|c|}
\hline $\begin{array}{l}\text { Auteur } \\
\text { (année) }\end{array}$ & $\begin{array}{l}\text { Pays/ } \\
\text { région }\end{array}$ & $\begin{array}{c}\text { Question(s)/ } \\
\text { objectif de l'étude }\end{array}$ & Méthodologie & Population & Principales conclusions/obstacles repérés \\
\hline $\begin{array}{l}\text { Hudson, } \\
\text { Heilemann et } \\
\text { Rodriguez } \\
(2012)(17)\end{array}$ & États-Unis & $\begin{array}{l}\text { Perspectives et } \\
\text { expériences des } \\
\text { fournisseurs de soins } \\
\text { primaires à l'égard } \\
\text { des obstacles et des } \\
\text { facteurs favorables à } \\
\text { l'offre d'un counseling } \\
\text { et d'un test volontaire } \\
\text { du VIH à tous les } \\
\text { patients âgés de } 13 \text { à } \\
64 \text { ans dans le cadre } \\
\text { d'un dépistage } \\
\text { annuel? }\end{array}$ & Entrevue & $\begin{array}{l}\text { Fournisseurs } \\
\text { de soins } \\
\text { primaires } \\
\text { (c.-à-d. } \\
\text { médecine } \\
\text { familiale, } \\
\text { médecine } \\
\text { interne et } \\
\text { pédiatrique) }\end{array}$ & $\begin{array}{l}\text { - Normalisation du dépistage du VIH (lequel ne } \\
\text { devrait pas être considéré différemment des } \\
\text { tests pour déterminer le taux de glycémie ou de } \\
\text { cholestérol ou la tension artérielle) } \\
\text { - Ressources et formation destinées à améliorer } \\
\text { les connaissances et la familiarité des } \\
\text { fournisseurs avec les lignes directrices } \\
\text { actuelles } \\
\text { - Information des patients sur le dépistage du } \\
\text { VIH } \\
\text { - Communication et style personnel (p. ex. } \\
\text { prendre le temps d'informer et de motiver les } \\
\text { patients) }\end{array}$ \\
\hline $\begin{array}{l}\text { Simmons et } \\
\text { al. (2011) (13) }\end{array}$ & États-Unis & $\begin{array}{l}\text { Obstacles et facteurs } \\
\text { favorables au test de } \\
\text { dépistage du VIH de } \\
\text { routine }\end{array}$ & Entrevue & $\begin{array}{l}\text { Fournisseurs } \\
\text { de soins de } \\
\text { santé }\end{array}$ & $\begin{array}{l}\text { - Intérêt et disposition du patient } \\
\text { - Assurance quant à la confidentialité } \\
\text { - Mise à disposition de documents et possibilité } \\
\text { de formation sur le VIH dans les cliniques } \\
\text { - Fournisseurs plus proactifs pour ce qui est de } \\
\text { proposer le dépistage }\end{array}$ \\
\hline $\begin{array}{l}\text { Myers, } \\
\text { Koester et } \\
\text { Dufour (2011) } \\
(21)\end{array}$ & États-Unis & $\begin{array}{l}\text { Obstacles à la mise } \\
\text { en œuvre et } \\
\text { l'expansion du } \\
\text { dépistage du VIH } \\
\text { Stratégies pour } \\
\text { surmonter ces } \\
\text { obstacles }\end{array}$ & Entrevue & $\begin{array}{l}\text { Administrateurs } \\
\text { du financement } \\
\text { et de la gestion } \\
\text { de programmes, } \\
\text { directeurs } \\
\text { médicaux/ } \\
\text { médecins } \\
\text { dispensant des } \\
\text { soins dans des } \\
\text { cliniques } \\
\end{array}$ & $\begin{array}{l}\text { - Supprimer les exigences obligatoires liées au } \\
\text { consentement et au counseling } \\
\text { - Faire du dépistage de routine une priorité } \\
\text { - Corriger les idées reçues parmi les fournisseurs } \\
\text { de soins quant à la disponibilité universelle du } \\
\text { test de dépistage }\end{array}$ \\
\hline
\end{tabular}

